\title{
O PODER SOBERANO EM JEAN-JACQUES ROUSSEAU
}

\author{
Marco Antônio Correa Bezerra ${ }^{1}$
}

Resumo: A questão fundamental dessa investigação será mostrar quais bases sustentam a ideia do poder soberano no interior do chamado Estado Moderno e como nele se manifesta a relação com seus membros. Para alcançar esse objetivo pretendemos inicialmente mostrar a busca destas bases que o pensamento de Jean-Jacques Rousseau persegue desde o Discurso sobre as ciências e as artes (1749), passando pelo Discurso sobre a Origem e os Fundamentos da Desigualdade entre os Homens (1755) até alcançar sua formulação mais completa em Do Contrato Social (1762), considerado o estudo mais influente da vida intelectual do autor. Nesta última obra, a legitimidade do comportamento se torna necessária para organizar os integrantes da sociedade, tornando coeso o corpo político. Para isso, os cidadãos se submetem a uma lei inviolável, a qual será validada pelos próprios membros do Estado. Portanto, delegam seu poder particular em direção à vontade geral, sendo cada homem considerado parte do poder soberano do Estado.

Palavras-chave: Poder. Estado. Lei. Soberania. Cidadão.

${ }^{1}$ Graduado em Filosofia. Mestrando em Filosofia pela Universidade Federal do Pará - UFPA. 
Antes de analisar a obra Do Contrato Social (1762) de Jean-Jacques Rousseau (1712 1778), se faz necessário reconstruir, brevemente, a trajetória das obras principais do cidadão genebrino até o seu amadurecido estudo político. A sua vida intelectual situa-se em um momento de crítica aos Estados absolutistas, nos quais os reis detinham todos os poderes, tanto o legislativo, quanto o executivo e o judiciário. Esse domínio real, portanto, seria a representação máxima da autoridade sobrenatural imposta pela igreja. No sentido oposto, na política vigente havia um intenso movimento liberal burguês, o qual buscava sua participação frente às decisões do poder absoluto representado pelo rei.

A primeira dessas obras é o Discurso Sobre as Ciências e as Artes de 1749, a qual conquista o prêmio como a melhor resposta a seguinte questão lançada pela Academia de Dijon no ano de 1750: “O restabelecimento das ciências e das artes terá contribuído para aprimorar os costumes?". A finalidade de Rousseau nesse texto é estruturar a forma de pensar sobre a política a partir de questões éticas, notavelmente percebida neste primeiro discurso: "Temos físicos, geômetras, químicos, astrônomos, poetas, músicos, pintores; não temos mais cidadãos" (CA, 1978, p. 349) ${ }^{2}$. O mérito desse esforço intelectual foi devido a profunda meditação, de um estudo sobre os conflitos da inserção do homem na sociedade, que se inicia desde a sua saída do estado natural até sua chegada ao mundo aclarado pela razão. Assim a investigação se dá conta de que esses dois elementos corrompem o comportamento do homem na sociedade, pois se estimava o caráter pela glória material adquirida pelas ciências e pelas artes em detrimento das virtudes:

\begin{abstract}
Aí está o efeito mais evidente de todos os nossos estudos, a mais perigosa de suas consequências. Não se pergunta mais a um homem se ele tem probidade, mas se tem talento; nem de um livro se é útil, mas se é bem escrito. [...] Que me digam, no entanto, se é comparável a glória, conferida ao melhor dos discursos premiados nesta academia, ao mérito de ter instituído o prêmio. (1978, p. 348).
\end{abstract}

Desse modo, o período Renascentista não valorizava o que seria fundamental para Rousseau, o apreço do ser humano pelo outro. O que havia era uma decadência moral crescendo simultaneamente com o progresso científico e artístico, já que as relações humanas eram pautadas na aparência. Cassirer reconhece a intenção de Rousseau nesta crítica: "Como enfatiza o Rousseau juge de Jean-Jacques, o ataque às artes e as ciências nunca tivera a intenção de atirar a humanidade de volta à sua barbárie original” (1980, p. 394). Rousseau

\footnotetext{
${ }^{2}$ Abreviaturas das obras de Rousseau: CS: Do Contrato Social; CA: Discurso sobre as ciências e as artes; EP: Discurso sobre Economia Política; DD: Discurso sobre a origem e os fundamentos da desigualdade entre os homens.
} 
estava destruindo a fantasia ridícula pela admiração daquilo que é inútil à vida social. Segue Rousseau (CA, 1978, pp. 335- 336):

A riqueza do vestuário pode denunciar um homem opulento, e a elegância, um homem de gosto; conhece-se o homem são e robusto por outros sinais - é sob o traje rústico de um trabalhador e não sob os dourados de um cortesão, que se encontrarão a força e o vigor do corpo. A aparência não é menos estranha à virtude, que se constitui a força e o vigor da alma.

Jean Starobinski resume essa diferença entre ser e parecer, a qual Rousseau critica nas relações sociais, da seguinte maneira: "Os benefícios das luzes se encontram compensados, e quase anulados, pelos inumeráveis vícios que decorrem da mentira da aparência" (1991, p. 15) $)^{3}$. Em seguida, concorda com Rousseau e denuncia esse declínio dos costumes gerado pelas artes e ciências de forma veemente: "um ímpeto de eloquência descrevera a ascensão triunfal das artes e das ciências; um segundo lance de eloquência nos arrasta agora em sentido inverso, e nos mostra toda a extensão da "corrupção dos costumes"” (Idem).

O próximo passo nessa trajetória até sua obra mais conhecida, Do Contrato Social, se estabelece publicamente em 1755, no seu segundo discurso, Sobre a Origem $e$ os Fundamentos da Desigualdade entre os Homens. Anteriormente, no ano de 1753, a Academia de Dijon lançou uma nova questão: "Qual é a origem da desigualdade entre homens e é ela autorizada pela lei natural?”. Ao qual Rousseau compete novamente, porém o prêmio vai para outro discurso de autoria do padre François Xavier Talbert. Na construção inicial da obra o pensador genebrino esclarece que um selvagem não reflete sobre o seu sofrimento, justamente para comprovar ao leitor que há uma diferença entre um selvagem e um homem moral:

À nossa volta, vemos quase somente pessoas que se lamentam de sua existência, inúmeras até que dela se privam assim que podem, e o conjunto das leis divinas e humanas mal basta para deter essa desordem. Pergunto se algum dia se ouviu dizer que um selvagem em liberdade pensou em lamentar-se da vida e em querer morrer. (1978, p. 251).

Este segundo discurso evidencia mais uma vez que de fato há esse constante afastamento do homem da natureza ao se socializar. Essa inserção acaba por corromper seu estável estado natural. Rousseau explica que na natureza não há consciência, por exemplo de conceitos como bondade e maldade:

\footnotetext{
${ }^{3}$ TO: STAROBINSKI, Jean. Jean - Jacques Rousseau: A transparência e o obstáculo; seguido de setes ensaios sobre Rousseau/ Jean Starobinki; Tradução de Maria Lúcia Machado. São Paulo: Companhia das Letras, 1991.
} 


\section{REVISTA APOENA - Per. dos Dis. de Fil. da UFPA \\ Belém, 2019, V. 1, N.1.}

Parece, a princípio, que os homens nesse estado de natureza, não havendo entre si qualquer espécie de relação moral ou de deveres comuns, não poderiam ser nem bons nem maus ou possuir vícios e virtudes, a menos que, tomando estas palavras num sentido físico, se considerem como vícios do indivíduo as qualidades capazes de prejudicar sua própria conservação, e virtudes aquelas capazes de em seu favor contribuir, caso em que se poderia chamar de mais virtuosos àqueles que menos resistissem aos impulsos simples da natureza (Idem).

O pensador genebrino sabe que o estado natural do homem é uma teoria, porém uma suposição necessária, precisamente para esclarecer o mal entendido deixado por Thomas Hobbes. O inglês confunde e considera equivalentes o estado de natureza e a condição de guerra. Rousseau critica intensamente a seguinte afirmação feita por esse pensador inglês:

Com isto se torna manifesto que, durante o tempo em que os homens vivem sem um poder comum capaz de os manter a todos em respeito, eles se encontram naquela condição a que se chama guerra: e uma guerra que é todos os homens contra todos os homens $(1974, \text { p. } 79)^{4}$.

Rousseau tem convicção de que o estado natural, sendo uma hipótese lhe servirá, logicamente para fundamentar a compreensão do ser humano dentro da sociedade:

Estendi-me desse modo sobre a suposição dessa condição primitiva por que, devendo destruir antigos erros e preconceitos inveterados, achei que devia pulverizálos até a raiz e mostrar, no quadro do verdadeiro estado de natureza, como a desigualdade, mesmo natural, está longe de ter nesse estado tanta realidade e influência quanto pretendem nossos escritores (1978, p. 259).

O homem selvagem segue seu instinto apenas para suprir a necessidade da autoconservação. O estado de natureza é estável, pois não prejudica o ciclo natural de vida do reino animal; não há guerra; não há exageros na natureza, segue a crítica de Rousseau a Hobbes: "Ele diz justamente o contrário por ter incluído, inoportunamente, no desejo de conservação do homem selvagem a necessidade de satisfazer uma multidão de paixões que são obra da sociedade e que tornaram as leis necessárias" (1978, p. 252). O suíço esclarece o legado confuso deixado por Thomas Hobbes, exatamente sobre o estado natural do homem:

Hobbes não viu que a mesma causa que impede os selvagens de usar a razão, como o pretendem nossos jurisconsultos, os impede também de abusar de suas faculdades, como ele próprio acha; de modo que poderia dizer que os selvagens não são maus precisamente porque não sabem o que é ser bons, pois não é nem o desenvolvimento das luzes, nem o freio da lei, mas a tranquilidade das paixões e a ignorância do vício que os impedem de proceder mal (...)" (1978, p. 252).

\footnotetext{
${ }^{4}$ LV: HOBBES, Thomas. Leviatã ou matéria e poder de um Estado e eclesiástico e civil. São Paulo, Abril Cultural, 1974. (Col. Os Pensadores)
} 
Thomas Hobbes falhou em seu estudo novamente por não analisar dois princípios fundamentais para compreender o que precede o início da racionalidade do homem ao adentrar ao estado artificial. Tais princípios antecedem a racionalidade, pois ainda não há reflexão no comportamento. A piedade seria um sentimento natural que se manifesta quando um selvagem se coloca no lugar de outrem que sofre, sendo uma relação íntima entre o animal espectador e o sofredor:

Um animal não passa sem inquietação ao lado de um animal morto de sua espécie; há até alguns que lhes dão uma espécie de sepultura, e os mugidos do gado entrando no matadouro exprimem a impressão que tem do horrível espetáculo que o impressiona (1978, p. 253).

O outro princípio observado por Rousseau (1978, p. 306), seria o amor de si que é um sentimento natural que leva todo animal a velar pela própria conservação e que, no homem dirigido pela razão e modificado pela piedade, produz a humanidade e virtude. O genebrino diferencia-o do amor próprio, pois este se caracteriza por ser um sentimento fictício e nascido na sociedade, que leva cada indivíduo a fazer mais caso de si do que de qualquer outro, que inspira a todos os males que mutuamente se causam e que constitui a verdadeira fonte da honra.

Segundo Rousseau o ser humano dotado de perfectibilidade tem a capacidade de aperfeiçoar seu comportamento, já que é adaptado por natureza a tendência de organizar sociedades para melhorar o convívio, dessa forma acaba por se afastar do estado de natureza. Aventurar-se então, a partir daí o homem selvagem a submissão de sua natureza à servidão civil, pois registra nessa relação a propriedade privada. Novamente Rousseau, necessita recorrer a uma hipótese lógica para edificar seu estudo político. Supõe que a sociedade civil constituiu a partir da primeira marcação de terreno feito por um homem: “o verdadeiro fundador da sociedade civil foi o primeiro que, tendo cercado um terreno, lembrou-se de dizer isto é meu e encontrou pessoas suficientemente simples para acreditá-lo” (1978, p. 259). Neste instante, logicamente, surge a desigualdade moral, pois esta depende da aceitação de outros homens.

Contudo, essa cronologia abrange não somente o tempo das obras de Rousseau, mas a organização no que diz respeito ao seu pensamento filosófico. Até o momento houve uma preocupação nesse estudo político com os motivos que levam à corrupção, será necessário organizar a sociedade com base nas leis, a partir do problema detectado. Nesse mesmo ano Rousseau publica na Enciclopédia o verbete Economia Política com o objetivo de organizar por meio de leis a comunidade, ou seja, as regras se tornam uma obrigação para manter a 
sociedade coesa. O suíço considera a economia política uma gestão que organiza o todo e a qual diferencia da soberania:

\begin{abstract}
Ainda é preciso insistir com os leitores para que distingam claramente a economia política, de que falei e que chamo de governo, da autoridade suprema, que chamo de soberania; distinção que consiste em que a primeira possui o direito legislativo, e a obriga em alguns casos a nação como um todo, enquanto a segunda só tem o poder executor e só pode obrigar os particulares (1995, p. 24).
\end{abstract}

Nota-se que a sociedade ou corpo político - chamado por Rousseau - se estabelece pela vontade "e essa vontade geral que tende sempre à conservação e ao bem-estar do todo e de cada parte e que é a fonte das leis, é para todos os membros do Estado a regra do justo e do injusto (1995, p. 25). Sendo por esse motivo, “em um governo bem policiado, jamais será dada alguma isenção por conta de qualquer desculpa” (1995, p. 29). Diferentemente da economia particular - âmbito privado - a economia pública administra de acordo com as leis, e essas leis devem estar adequadas à vontade geral, pois esse governo somente permanecerá se estiver alinhado com o interesse público. O Estado incumbido de preservar a vida, dando direito a propriedade, garantirá os compromissos dos cidadãos como acordo legal na sociedade civil. Além disso, para a manutenção do Estado e do governo será exigido contribuições como recursos para o bom funcionamento das finanças públicas. Rousseau ressalta a dificuldade na administração econômica do Estado:

Assim, se as contribuições são voluntárias não produzem nada, e se são forçadas são ilegítimas; a dificuldade de uma justa e sábia economia consiste nessa cruel alternativa entre deixar perecer o Estado ou atacar o direito de propriedade, que é sua base $(1995,44)$.

Dessa maneira, essa base fundamenta o pacto social, sendo conservada para a condição do bem-estar social. O genebrino, portanto, está afinal culminando o ponto central do seu estudo político no que veremos chamado de contrato social, constituído pelo corpo político, visto como Estado quando passivo e soberano quando ativo. O principal embasamento desse pensador genebrino se encontra na a obra, Do Contrato Social de 1762. Até aqui foi visto um análise progressiva e fundamental para compreender o que pode ser considerado o cerne do pensamento de Rousseau. Para Ernst Cassirer o longo e amadurecido processo de elaboração desse estudo deve ser entendido como uma trajetória: 


\section{REVISTA APOENA - Per. dos Dis. de Fil. da UFPA \\ Belém, 2019, V. 1, N.1.}

considerava, ao contrário, como uma extensão coerente desses ensaios, seu acabamento e perfeição (1980, p. 394).

A obra tem a finalidade de compreender em que condições se dá a passagem da liberdade natural para o condicionamento social, portanto, por uma convenção que será legitimada perante o Estado de deveres. Ernst Cassirer exalta a grandeza da obra:

O Contrat social proclama e glorifica um absolutismo irrestrito. Toda vontade particular e individual é esmagada pelo poder da volonté générale. O próprio ato de integrar-se ao Estado significa a renúncia completa a todos os desejos particulares. $\mathrm{O}$ homem não se entrega ao Estado e à sociedade sem se entregar a ambos completamente. Pode-se falar de uma verdadeira "unidade" do Estado somente se os indivíduos se fundem nesta unidade e desaparecem nela (1980, p. 392).

A sociedade se estabelece como algo superior ao indivíduo, uma configuração dita sagrada. Essa organização social se constitui por convenção: “a ordem social, porém, é um direito sagrado que serve de base a todos os outros. Tal direito, no entanto, não se origina na natureza: funda-se, portanto, em convenções" (1978, p. 22). Quando o genebrino menciona "convenções", se refere a tudo àquilo que é criação humana, como por exemplo, a passagem da liberdade natural à liberdade artificial. Pois o homem selvagem não nasce humano, sua natureza racional torna-o humano à medida que se agrega a outros formando a sociedade. Essa agregação, convencionada, possibilita ao ser humano encontrar o direcionamento adequado para validar seus costumes perante a comunidade.

No segundo capítulo da primeira parte dessa obra, Rousseau nos diz que a família pode ser considerada a primeira associação natural, vista como sociedade primária: "A mais antiga de todas as sociedades, e a única natural, é a da família” (1978, p. 23). No estado natural o que mantém a relação de aproximação entre os indivíduos - pai e filhos - é a necessidade de conservação: “(...) ainda assim só se prendem os filhos ao pai enquanto dele necessitam para a própria conservação" .

Se os filhos continuarem a manter essa ligação com o pai, depois da maturidade, considera-se uma convenção, ou seja, algo produzido pelo ser humano: "Se continuam unidos, já não é natural, mas voluntariamente, e a própria família só se mantém por convenção" . O genebrino continua no segundo capítulo: "Sua primeira lei consiste em zelar pela própria conservação, seus primeiros cuidados são aqueles que se deve a si mesmo, e, assim que alcança a idade da razão, sendo o único juiz dos meios adequados para conservar-se, torna-se, por isso, senhor de si” 
Comparável, Rousseau diz que a família pode ser considerada a primeira amostra de sociedade política. Sendo o pai semelhante ao soberano e o povo aos filhos, livres, que teriam autonomia na sociedade ao amadurecerem. Sobre essas duas concepções, o suíço se refere à obra $O$ Direito da Paz e da Guerra do jurista Grotius, na qual o holandês diz que a escravidão é um exemplo evidente de que nem todos os governados delegam seu poder particular ao poder soberano. Rousseau critica o jurista, devido a equivocada interpretação do termo "escravidão" na obra Política de Aristóteles. Rousseau concorda com Aristóteles, pois escravo é considerado todo aquele que está preso pelos desejos particulares de sua natureza: "[...] do estado civil a liberdade moral, única a tornar o homem verdadeiramente senhor de si mesmo, porque o impulso do puro apetite é escravidão, e a obediência à lei que se estatuiu a si mesma é liberdade" (1978, p. 37).

Quando ampliado ao contexto social se torna necessário o que Rousseau nomeia de pacto social caracterizado analogamente como a família por uma convenção, caso contrário se homens permanecem no estado primitivo, pereceriam. Não há outro meio, senão buscar a conservação unindo forças entre os cidadãos na sociedade: "encontrar uma forma de associação que defenda e proteja a pessoa e os bens de cada associado com toda a força comum, e pela qual cada um, unindo-se a todos, só obedece contudo a si mesmo, permanecendo assim tão livre quanto antes" (1978, p. 32). O cidadão manteria sua liberdade por meio desse acordo social, convencionada. Seria condição igual a todos os membros da comunidade, preservando os seus direitos legitimados pelos próprios seres humanos: "Cada um de nós põe em comum sua pessoa e todo o seu poder sob direção suprema da vontade geral, e recebemos, enquanto corpo, cada membro parte indivisível do todo" (1978, p. 33). Ernest Cassirer concorda com o genebrino: "não é a renúncia a esta lei nem a libertação dela o que determina o caráter genuíno e verdadeiro da liberdade, mas sim o livre consentimento a ela" (1980, p. 395). O homem controla seus desejos particulares para se tornar um agente público, capaz de agir em benefício do corpo moral e coletivo, dando coesão à sociedade:

Essa pessoa pública, que se forma, desse modo, pela união de todas as outras, tomava antigamente o nome de cidade e, hoje, o de república ou de corpo político, o qual é chamado de Estado quando passivo, soberano quando ativo, e potência quando comparado a seus semelhantes. Quanto aos seus associados, recebem eles, coletivamente, o nome de povo e se chamam, em particular, cidadãos, enquanto partícipes da autoridade soberana, e súditos enquanto submetidos às leis do Estado. Esses termos, no entanto, confundem-se freqüentemente e são usados indistintamente; basta saber distingui-los quando são empregados com inteira precisão (Idem). 
A finalidade do corpo coletivo se estabelece no interesse comum, contudo na vontade geral. Dessa maneira a sociedade se torna válida tendo como suporte o bem comum e assim deve ser governada. Porém esse interesse não é considerado o de todos - soma de todos os particulares -, mas de cada membro do corpo político. Em cada vontade privada prevalece o impulso natural, caracterizado pelo egoísmo. Ao contrário da vontade geral que aplica o princípio de igualdade legal a todo o liame social.

Portanto quando se unir essas diferenças, resultará sempre na vontade geral e se houver uma vontade que se prevaleça a todas as outras não haverá mais a adesão de diferenças, mas uma diferença singular, isto é uma opinião particular. Tendo como base esse discurso lógico, a soberania acaba por ser o exercício da vontade geral, e o poder soberano o próprio povo que abastece a teoria nesta relação: "afirmo, pois, que a soberania, não sendo senão o exercício da vontade geral, jamais pode alienar-se, e que o soberano, que nada é senão um ser coletivo, só pode ser representado por si mesmo" (1978, p. 44). Dessa forma engana-se quem sugere que o povo se corrompe, pois, a vontade geral tende sempre ao interesse público quando legitimada. A legitimidade, assim se estabelece na vontade geral: "já disse não haver vontade geral visando objeto particular" (1978, p. 54). A universalidade então dessa vontade estatui a lei que por sua vez adota o povo como poder soberano dentro do Estado, sendo seu autor a qual está também submetido.

\section{REFERÊNCIAS BIBLIOGRÁFICAS}

ARISTÓTELES. A política. Tradução Mario da Gama Kury. Brasília: Editora Universidade de Brasília, 1985.

CASSIRER, Ernst. A questão de Jean- Jacques Rousseau. In: QUIRINO, Célia Galvão; SOUZA, Maria Teresa Sadek R. de. O pensamento político clássico: Maquiavel, Locke, Montesquieu, Rousseau. São Paulo: T. A. Queiroz, 1980.

COROA, Pedro Paulo. Rousseau ortodoxo. Kínesis, Marília, São Paulo - SP, v. V, n. 09, pp. 134-140, 2013.

DENT, N.J.H. Dicionário Rousseau. Tradução Álvaro Cabral. Rio de Janeiro: Jorge Zahar, 1996.

HOBBES, Thomas. Leviatã ou matéria e poder de um Estado e eclesiástico e civil. São Paulo, Abril Cultural, 1974. (Col. Os Pensadores) 
ROUSSEAU, Jean-Jacques. Discurso sobre a origem e os fundamentos da desigualdade entre os homens. São Paulo, Abril Cultural, 1978, p. 201-315. (Col. Os Pensadores).

ROUSSEAU, Jean-Jacques. Discurso sobre as ciências e as artes. São Paulo, Abril Cultural, 1978, p. 321-333. (Col. Os Pensadores).

ROUSSEAU, Jean-Jacques. Do Contrato Social. São Paulo, Abril Cultural, 1978, p. 1-145. (Col. Os Pensadores).

ROSA, Marlene de Fátima. A concepção de legitimidade do poder em Rousseau. 2014. 95 f. Dissertação (Mestrado em Filosofia) - Filosofia do Centro de Ciências Humanas e Sociais, Universidade Estadual do Oeste do Paraná, Toledo, 2014.

STAROBINSKI, Jean. Jean-Jacques Rousseau: A transparência e o obstáculo; seguido de setes ensaios sobre Rousseau/Jean Starobinki; Tradução de Maria Lúcia Machado. São Paulo: Companhia das Letras, 1991. 